\title{
Study on the Critic Ablation Property of 2D Carbon Reinforced Silicon Carbide (C/SiC) Laminated Composites via CVI Process
}

\author{
Changwan Min, Li Jing, Bin Fu, Geliang Sun, Zhanwei Cao \\ Science and Technology on Space Physics Laboratory, Beijing, China \\ Email: minchangwan@126.com
}

How to cite this paper: Min, C.W., Jing, L., Fu, B., Sun, G.L. and Cao, Z.W. (2017) Study on the Critic Ablation Property of 2D Carbon Reinforced Silicon Carbide (C/SiC) Laminated Composites via CVI Process. Journal of Materials Science and Chemical Engineering, 5, 76-80.

http://dx.doi.org/10.4236/msce.2017.51011

Received: October 24, 2016

Accepted: January 1, 2017

Published: January 4, 2017

\begin{abstract}
Two dimensions (2D) C/SiC laminated composites is the material with isotropic properties in laminated sheets, which is considered as a promising thermal skin for aircrafts. There are intense thermal flux and thermal impact at the local interference region during the flight of the aircrafts. Therefore, mastering ablation and mechanical properties of $2 \mathrm{D} \mathrm{C/SiC} \mathrm{laminated} \mathrm{compo-}$ site under extreme environments become the guild lines for the designs of the flight corridor and the aircraft security. This paper presents the experimental results of the ablation and thermal impact of $\mathrm{C} / \mathrm{SiC}$ composites under different thermal environments (thermal flux $\sim 5 \mathrm{MW} / \mathrm{m}^{2}$ ), which were carried out with the equipments of free-jets and conduct pipes. The effects on the ablation and mechanical properties of the $\mathrm{C} / \mathrm{SiC}$ composites are studied, including gas pressure, thermal temperature, and the rates of temperature increasing and decreasing. The results show that the active oxidation and ablation behaviors of $2 \mathrm{D} \mathrm{C} / \mathrm{SiC}$ laminated composites under the thermal flux $5 \mathrm{MW} / \mathrm{m}^{2}$ consist with that of theoretical simulations. The critical failure conditions of $2 \mathrm{D}$ $\mathrm{C} / \mathrm{SiC}$ laminated composite is also provided for the enveloping designs of the whole composites lightweight aircrafts.
\end{abstract}

\section{Keywords}

2D, C/SiC, Critic, Ablation Property, Experimental

\section{Introduction}

Continuous carbon fiber-reinforced silicon carbide $(\mathrm{C} / \mathrm{SiC})$ composites have been developed for high temperature structural applications such as engines and thermal protection system [1]. Two-dimensional C/SiC composite material is laminated isotropic materials, as the skin material of aircrafts' thermal structure 
with good application prospect. But because of the interference between shock waves and boundary layers, an intense heat flux is induced at aircrafts' local area. So, for the flight security and designing of the flight corridor, researchers usually require thermal skin not to be ablated even in extreme environment. It is obvious that there is a large safe coefficient between designed performance and actual needed performance. In order to realize satisfied aircraft design, people need to know the ultimate ablation performance of $\mathrm{C} / \mathrm{SiC}$ composites. This paper uses the data of arc wind tunnel experiments [2] and calculated results to predict $\mathrm{T}$, ablation rate and ablation area, which supports the fine design of $\mathrm{C} / \mathrm{SiC}$ composite aircraft.

\section{Ablation Calculation Method of C/SiC Composite Material Selecting a Template}

$\mathrm{C} / \mathrm{SiC}$ composite material is mainly made of carbon fiber, carbon interface layer (PyC) and silicon carbide substrate. The ablation [3] behavior of C/SiC composite is dominated by $\mathrm{SiC}$ component. There are three chemical ablation modes: passive oxidation, active oxidation and melting/decomposition.

1) In the passive oxidation mode, the diffusion of oxygen is limited by the $\mathrm{SiO}_{2}$ film generated at the surface and so the oxidation of $\mathrm{SiC}$ matrix is prevented. In this mode, the ablation needs not to be considered.

2) In the active oxidation mode, when the $\mathrm{SiO}_{2}$ evaporation rate is greater than the rate of $\mathrm{SiO}_{2}$ formation, $\mathrm{SiO}_{2}$ film is difficult to maintain and $\mathrm{SiC}$ matrix is continuously oxidized. Due to the ablation of SiC surface, interfacial layer and the carbon fiber will also be exposed, directly react with oxygen, and be ablated. In this mode, the ablation must be considered.

3) In the melting/decomposition mode, it generally occurs above $2600^{\circ} \mathrm{C}$, with numerous reactions and complicated processes. For engineering applications, $\mathrm{C} / \mathrm{SiC}$ composite material is usually thin-walled structure, bearing both load and heat and usually cannot meet the requirements above $2600^{\circ} \mathrm{C}$. That is beyond the requirements of anti-ablation design. On special occasions, because of the existence of carbon fibers, people use carbon sublimation ablation mode to value the ablation and finish the anti-ablation design of $\mathrm{C} / \mathrm{SiC}$ composite materials.

For the active oxidative ablation of $\mathrm{C} / \mathrm{SiC}$ composites, the reaction between silicon carbide and oxygen is shown as the Equation (1):

$$
\mathrm{SiC}(\mathrm{s})+\mathrm{O}_{2}(\mathrm{~g}) \rightarrow \mathrm{SiO}(\mathrm{g})+\mathrm{CO}(\mathrm{g}) \text {. }
$$

The reaction between carbon atoms and oxygen, known as "Combustion Glowing", is shown as the Equation (2):

$$
2 \mathrm{C}(\mathrm{s})+\mathrm{O}_{2}(\mathrm{~g}) \rightarrow 2 \mathrm{CO}(\mathrm{g}) \text {. }
$$

For the $\mathrm{C} / \mathrm{SiC}$ composite, according to the mass fraction of carbon and silicon carbide, a dimensionless mass ablation database is built with the results under different temperature and pressure.

The calculation procedure is as follows: first choose ablation mode, if it is confirmed neither thermochemical ablation nor passive oxidation model, $\mathrm{C} / \mathrm{SiC}$ 
composite materials will not be ablated; if it is confirmed the occurrence of thermochemical ablation or active oxidation model, the temperature field should be solved based on thermal environmental conditions, and then the ablation mode need to be confirmed based on the results of temperature; if thermochemical ablation or active oxidation mode occurs, the temperature history and thermal environmental conditions (including the pressure, heat, enthalpy) should be focused. The ablation rate will be obtained based on the dimensionless mass ablation database.

\section{Experimental Study on Ultimate Ablation Performance of C/SiC Composites}

The experiments [4] in arc wind tunnels were carried out to test the ablation performance of the SiC skin. Arc wind tunnel is composed of arc heater, mixing chamber, supersonic nozzle, test section, water cooling model support, diffuser, the pressure stabilizing chamber, cooler, vacuum system and so on. The nozzle used in the experiments is the Laval nozzle. The vacuum tank volume is $500 \mathrm{~m}^{3}$ and the highest vacuum is up to $200 \mathrm{~Pa}$.

According to the experimental parameters, the sample's surface temperature is above $2000^{\circ} \mathrm{C}$ and the average dimensionless mass ablation rates of 3 samples were about 0.245 . The theoretical value of ablation rate is 0.227 , only $7.9 \%$ difference to the tested results.

Take one model as an example. From the experimental video, there were some spots (Figure 1) at the high state, and the model surface started to melt. Based on the calculation model, the active oxidation started in the early stage and gaseous $\mathrm{SiO}$ was generated without melting. But in order stages, $\mathrm{SiO}_{2}$ was generated via passive oxidation and the temperature was beyond $1700^{\circ} \mathrm{C}$, so the surface started to melt. After the experiment, the surface of the model revealed exposed fibers and coating had been ablated.

Under the high enthalpy and low pressure conditions, Arc wind tunnel is suitable to simulate the hypersonic flight environment. Line ablation rate and Dimensionless quality ablation rate at thermal flux $\sim 5 \mathrm{MW} / \mathrm{m}^{2}$ are determined.

A higher state experiment was carried out and the install diagram was shown in Figure 2.

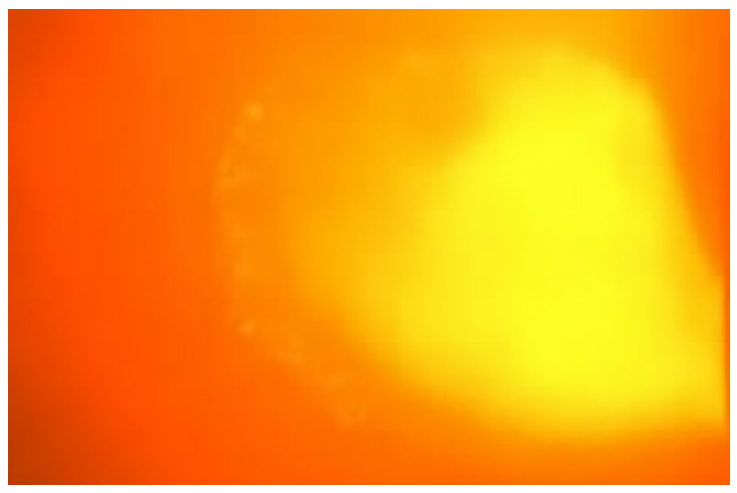

Figure 1. Surface ablation in the model 1\# experiment. 
According to the experimental condition parameters, the dimensionless mass ablation rates were 0.364 , a small difference to theoretic value 0.31 . The surface temperature was expected to be above $2600^{\circ} \mathrm{C}$ and the melting/decomposition occurred. Figure 3 shows the surface morphology of 2\# sample.

\section{Summary}

Ceramic matrix composites are ideal heat shield materials for reusable spacecrafts re-entering the Earth atmosphere. The interactions between the surface and the surrounding reactive gas determine the total heat flux to the wall and become design drivers for the thermal protection system [5]. In aircraft design, in order to obtain better cost-effectiveness, the limitations of the space and parts on the aircraft tend to be strict, and the request for fine design is demanded. The reach on the ultimate ablation performance of $\mathrm{C} / \mathrm{SiC}$ composite can be used to improve the design and the reliability of the aircraft. This paper presents $\mathrm{C} / \mathrm{SiC}$ composite ablation experimental method and calculation method, the results of test and calculation agree well, which is useful to design the flight corridor. The validity of the temperature/ablation calculation method is confirmed for $\mathrm{C} / \mathrm{SiC}$

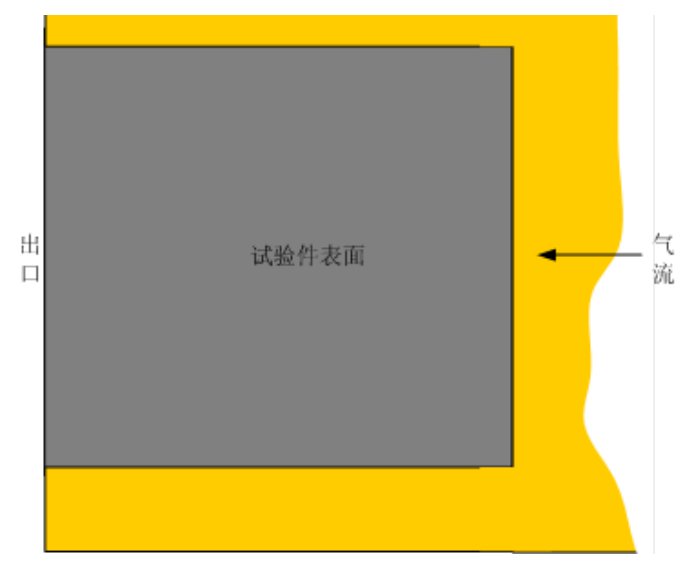

Figure 2. Schematic diagram of test parts installation.

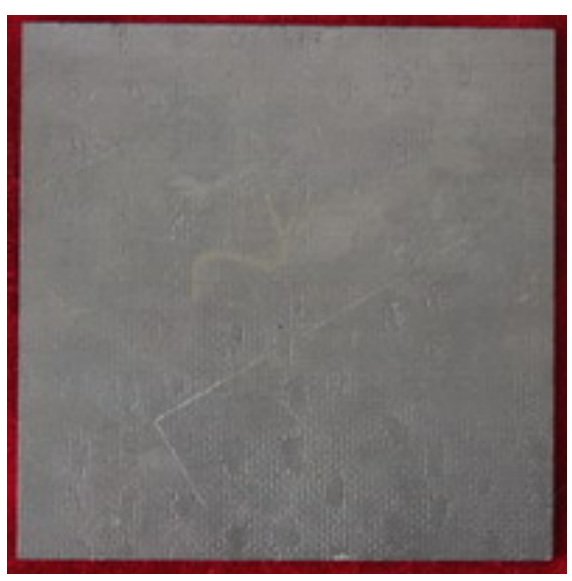

(a)

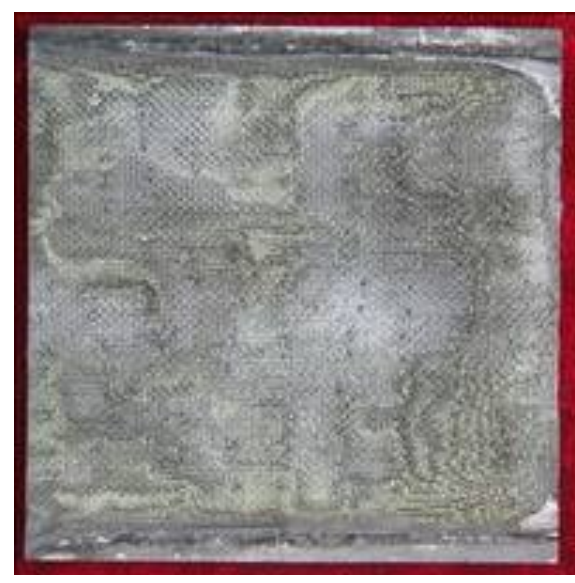

(b)

Figure 3. Morphology of the model before and after ablation. (a) Before the experimental. (b) After the experimental. 
composites.

\section{References}

[1] Tong, C.G., Cheng, L.F., Zhang, L.T. and Xu, Y.D. (2008) Preparation and Ablation Properties of C/SiC-(W-C) Composite Materials. Journal of Materials Science and Engineering, 26, 12-15.

[2] Pichon, T., Parenteau, R., Soyris, P., Foucault, A., Parenteau, J.M., Prel, Y. and Guedron S. (2009) CMC Thermal Protection System for Future Reusable Launch Vehicles: Generic Shingle Technological Maturation and Tests. Acta Astronautica. https://doi.org/10.1016/j.actaastro.2009.01.035

[3] Lee, Y., Kim, J., Yang, K. and Kim, S. (2007) Comparison of Plastic Ablation Materials of Capillary Discharge. 2007 16th IEEE International Pulsed Power Conference, June 2007.

[4] Pichon, T., Barreteau, R., Soyris, P., Foucault, A. and Parenteau. J.M. (2009) CMC Thermal Protection System for Future Reusable Launch Vehicles: Generic Shingle Technological Maturation and Tests. Acta Astronautica, 65, 165-176. https://doi.org/10.1016/j.actaastro.2009.01.035

[5] Panerai, F. and Chazot, O. (2012) Characterization of Gas/Surface Interactions for Ceramic Matrix Composites in High Enthalpy, Low Pressure Air Flow. Materials Chemistry \& Physics, 134, 597-607.

https://doi.org/10.1016/j.matchemphys.2012.03.036

Submit or recommend next manuscript to SCIRP and we will provide best service for you:

Accepting pre-submission inquiries through Email, Facebook, LinkedIn, Twitter, etc. A wide selection of journals (inclusive of 9 subjects, more than 200 journals) Providing 24-hour high-quality service User-friendly online submission system Fair and swift peer-review system Efficient typesetting and proofreading procedure Display of the result of downloads and visits, as well as the number of cited articles Maximum dissemination of your research work

Submit your manuscript at: http://papersubmission.scirp.org/

Or contact msce@scirp.org 